\title{
Possible Mesoamerican Naked-eye Observation of Sunspots - VI: Evidence from Yaxchilan Lintel 48
}

\author{
Richard R. Zito \\ Summerhaven Observatory, USA
}

Copyright $\subseteq 2017$ by authors, all rights reserved. Authors agree that this article remains permanently open access under the terms of the Creative Commons Attribution License 4.0 International License

\begin{abstract}
Many pre-telescopic naked-eye observations of large sunspot displays exist in the historical records. The most famous of these observations come from China, Japan, Korea, and Greece, but other cultures have made them as well. Pictorial evidence on dated monuments suggests that naked-eye sunspot displays may have been recorded in Mesoamerica as well. In this regard, Yaxchilan Lintel 48 is of particular interest. After a century long gap in naked-eye sunspot observations from Asia, an outstanding cluster of events began in $499 \mathrm{AD}$ and terminated on April 7, 513. Within 5 years of this latter date, Joy b'alam (Knot-eye Jaguar I) was captured and, following an interregnum, K'inich Tatb'u (Skull II; Knot-eye's brother) ascended the throne in 526. In retrospect, Mayan priests might have associated the sunspot displays with the change in political power, and recorded their observations on historical Lintel 48 , dated to $526 \mathrm{AD}$, by the device of a spotted Sun God.
\end{abstract}

Keywords Maya, Yaxchilan, Lintel 48, Sun God, Sunspots

\section{Background: The Larger Context}

Our Sun is a four and a half billion year old variable star with active and quiet periods marked by the presence and absence of sunspots. Its surface (photosphere) has been studied in detail ever since Galileo turned his telescope toward the Sun in 1610. And, the 11-year sunspot cycle is well established. Prior to 1610, astrophysicists must rely on historical sunspot records and indirect information (such as auroral activity, atmospheric carbon-14 analysis, etc.) to judge solar activity levels. Sunspot cycles of approximately five hundred years and two thousand years are suspected [1, 2]. Reports from the Far East (China, Japan, and Korea) [3] have been particularly useful for such studies because these ancient cultures had astronomical traditions, a written language, a numerical system, and a calendar. Therefore, researchers today can be reasonably sure that these historical reports were in fact describing sunspots on the stated dates. However, there are problems. First, there appear to be gaps in the historical record, and it is uncertain whether these gaps are real or simply reflect a lack of interest in making such observations. Second, the observations don't go back in time as long as astronomers would like. And third, the written descriptions accompanying some of the ancient observations have lead some scholars to believe that a few of the "sunspot" observations were actually phenomena within the Earth's atmosphere. In short, it would be very helpful for solar modeling if other sunspot records existed, independent of the Far Eastern observations cited above. This is especially true for records older than 2000 years BP, which are very sparse. In this regard, there are many astronomical traditions to choose from $[4,5,6,7]$.

Records from the Indian subcontinent seem promising [4, $3,7]$. And, there has been found a very suggestive legend in Indian folklore implying observation of sunspots [8]. But, dating such legends is difficult. Furthermore, the most ancient, and therefore the most interesting, records from India are in a script from the Indus Valley Civilization (c. $2500 \mathrm{BC}$ ) that is still un-deciphered [9].

Moving further west, the Greeks are known to have left clear sunspot references [10]. And, there is also valuable information to be mined from Egyptian/Arabic/Islamic sources. The Nilometer records [11] that measure the height of the Nile waters are particularly useful because this data series, that starts in pharaonic times and extends into modern times via Islamic scholarship, is one of those terrestrial data sets that is approximately phase locked to solar activity. Some of this Nilometer data has already been used in the second publication of this series on Mayan sunspot observations [12] to correlate the active Sun with the presence of the spotted Sun God in the Dresden Codex. Also, some non-standard solar images exist in ancient Egyptian art. For example, the apparent oblateness of the rising Sun due to atmospheric effects has been depicted [13]. The solar disk is particularly easy to observe at sunrise and sunset over the Sahara due to suspended dust 
particles, and the ancient Egyptians certainly did observe [14]. However, a decision on sunspots is still pending. Examination by the author of Islamic artifacts in museum collections around the world has not yet revealed any obvious pre-telescopic sunspot data. Available translated Islamic astronomical literature contains the usual fare of architectural alignments [15], eclipses, planetary conjunctions [16], etc., but nothing on sunspots was found [5]. However, new discoveries in the Islamic literature are still being made [17], and it is clear that the methods to be employed in observing the Sun were well understood in the Middle Eastern Islamic world [18]. Unfortunately, many potentially interesting manuscripts have simply been lost [18].

In Africa, south of the Arab world, there is a Zambesi myth that clearly indicates sunspot observation [19]. Again, however, dating such a myth is problematic.

In medieval Europe, there are reports of sunspots, solar prominences, and aurora from Russia [20, 21]. European records of aurora [22] provide precise information on solar activity that can be used to corroborate observations from Far East Asia. Many of these records go all the way back to ancient Rome [23].

Finally, there is information from Mesoamerica. The Maya have a long astronomical tradition (especially solar observation), invented writing, a numerical system, and a calendar (all deciphered). These facts make the Maya a prime candidate for acquisition of sunspot data. The very first suggestion that the Maya may have observed sunspots came from Galindo Trejo and Allen in 2005 [24]. The Fresco Hall, at the southern end of the Central Plaza of the Post-Classic Mayapan ruins, shows descending personages inside Sun circles of various panels. Trejo and Allen suggested that this might represent a Venus transit, or a naked-eye sunspot interpreted as Venus inside the solar disk by Mayan priest/astronomers. It should also be noted that, in addition to the Maya, other Mesoamerican people may be a source of sunspot information as well. For example, there is a pre-Columbian Aztec myth that has a Sun God with "dirty marks" on his face $[19,25]$. However, some Mesoamerican scripts, which might contain valuable information, are still un-deciphered $[9,26]$. Data may also be available from rock art in the southwestern U.S. since the Anasazi (including the Chaco Canyon culture) are known to have had contact (direct or indirect) with Mesoamerica, as judged from trade items found in ruins (e.g. tropical bird feathers) [27].

\section{Background to Mayan Astronomical Observations}

The Sun God of the Mayan pantheon is often depicted with three facial spots on his cheek forming a small equilateral triangle. At other times the spots are absent. There are three theories about this curiosity. Fialco [28] has suggested that the spotted Sun God is an emblematic device of the Tikal dynasty. However, this device is also known from sites and dynasties not connected with Tikal or its rulers $[29,30]$. Two other suggestions were made by Milbrath [30]. Perhaps the Sun God's facial markings are death spots or jaguar spots. Neither of these hypotheses has proven completely acceptable because the Sun God is associated with growth (not death), and the jaguar is a night animal. However, there is a fourth possibility. Perhaps the artistic device of the spotted Sun God is simply a direct reflection of observed solar activity by Mayan priest/astronomers; although no direct evidence, such as a table of naked-eye sunspot observations, is known to exist $[30,31]$. Nevertheless, the presence of a spotted Sun God in Mayan art correlates with high solar activity, while the absence if cheek spots correlates with a quiet Sun [12, 29, $32,33,34]$. The selection of Mayan artifacts for study has been dictated by four rules [12]: 1) the artistic motif must be present (Sun God with or without spots), 2) the artifact upon which the image occurs must be dated or dateable. 3) solar activity levels must be verifiable by direct observation from some ancient culture (typically, China, Japan, or Korea), and 4) observations must be substantiated by scientific data (i.e. auroral activity, carbon-14 measurements, tree ring analysis, etc.). All these criteria, taken together, are difficult to satisfy. Therefore, the number of artifacts that are capable of analysis is limited. In this paper only two artifacts will be analyzed. The primary artifact is Lintel 48 from Yaxchilan. A secondary, related artifact, from Baking Pot, Belize will also be discussed in section 7 of this paper.

\section{The Site - Yaxchilan and Lintel 48}

The Mayan city state of Yaxchilan lies near the border between Mexico and Guatemala (Figure 1) in the heart of the Mayan cultural zone on the Usumacinta River. The river itself forms a natural "moat" around the city with a single southern entry point (Figure 2). Additional security was furnished by perching building clusters on the tops and slops of hills within the city (Figure 3). From the careful site selection alone, one might guess that war was an important part of life in Yaxchilan. The city state flourished from about $360 \mathrm{AD}$ to $810 \mathrm{AD}$, and is particularly known for its carved stone lintels with militaristic and political messages. There are 58 lintels spanning the doorways of major structures. However, it is structure 12 (Figure 4) and the fine-grained limestone Lintel 48 (Figure 5A) that is of special interest in this report because, as will be discussed in detail below, it shows something very important $-a$ solar deity with three cheek spots forming a small, more or less equilateral triangle. Objects of this kind, as has been demonstrated in the previous publications of this series, often postdate a major naked-eye sunspot display that predates an important coincident change in political power. Lintel 48 is no exception to this rule! 


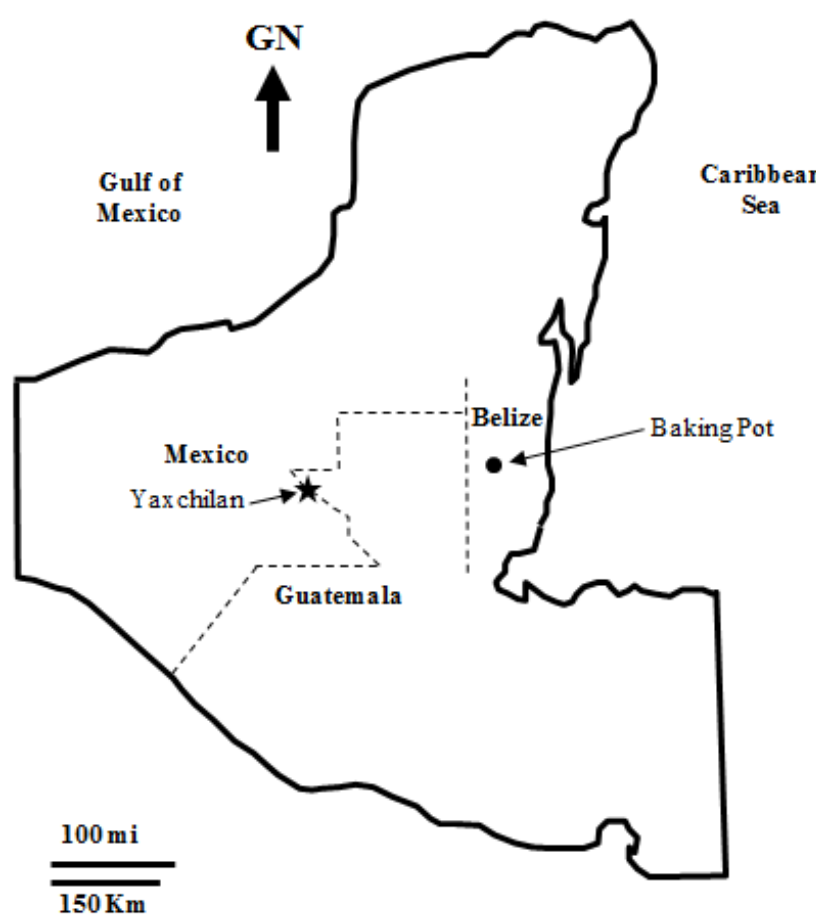

Figure 1. General location of the Yaxchilan and Baking Pot sites. GN is the geographical north. Map by author.

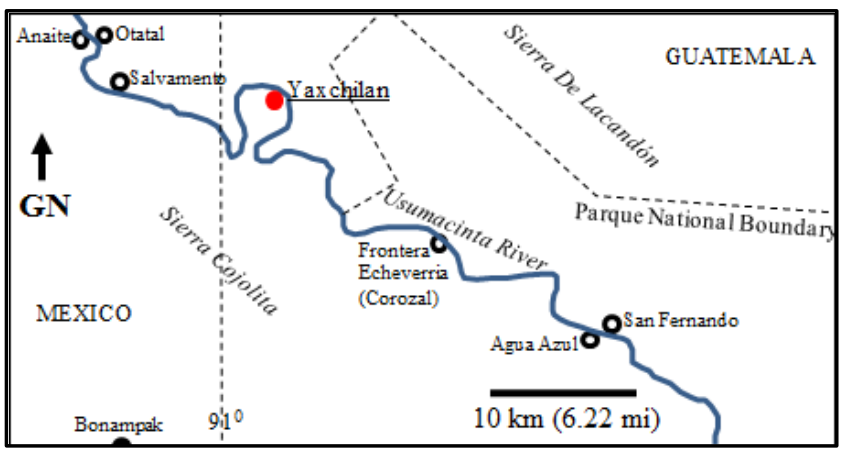

Figure 2. Close-up of Yaxchilan site location. GN is the geographical north. Map by author.

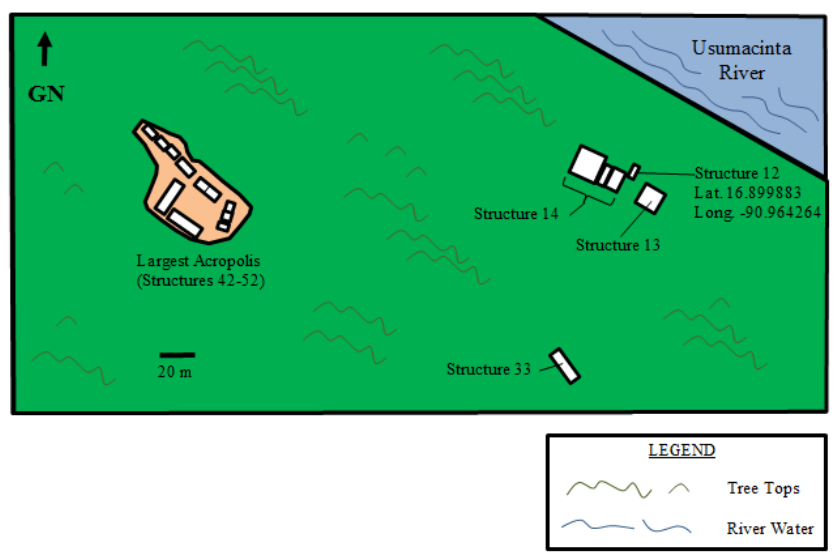

Figure 3. Partial site map of Yaxchilan by the author. In addition to Structure 12, several key landmarks are shown. The sand bank at the river's edge has been drawn as a straight line here to mark its more or less current "average" position. GN is the geographical north.

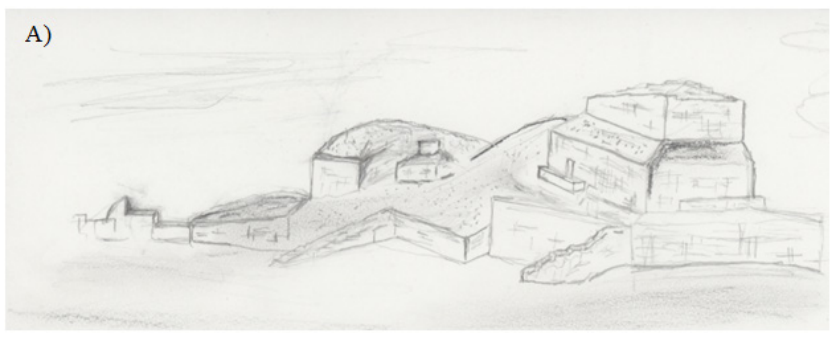

B)

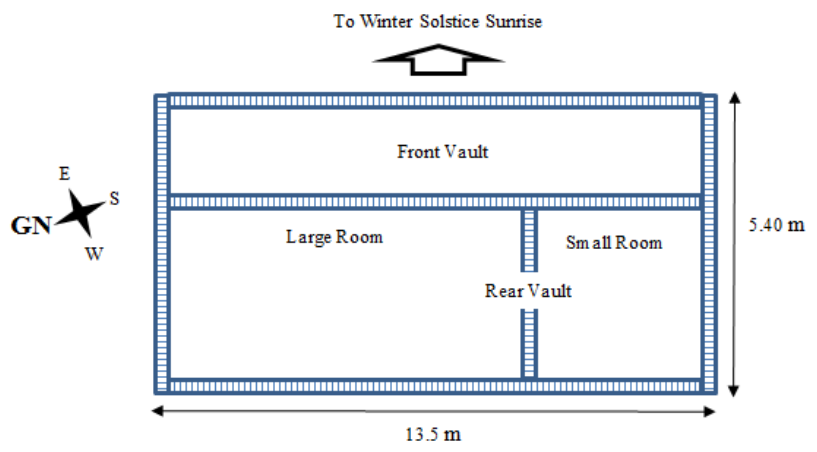

C)

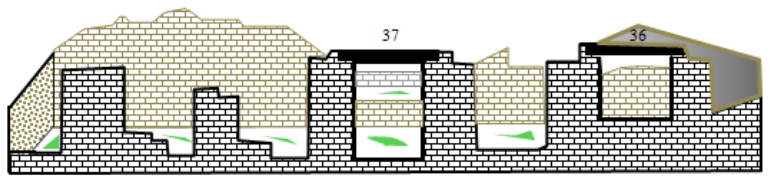

Figure 4. Structure 12. A) West view of Structures 12 and 13. B) Floor plan of Structure 12. GN is the geographical north. C) Isometric perspective view of west wall of Structure 12. Of 8 Lintels $(34,35,36$, $37,48,49$, and 60), only two (36 and 37) are still in situ. All the other lintels have fallen, including Lintel 48 , which was found broken in a debris pile outside the building near its SW corner. Only one piece of Lintel 48 has been conserved, the others have been lost. All drawings by author.
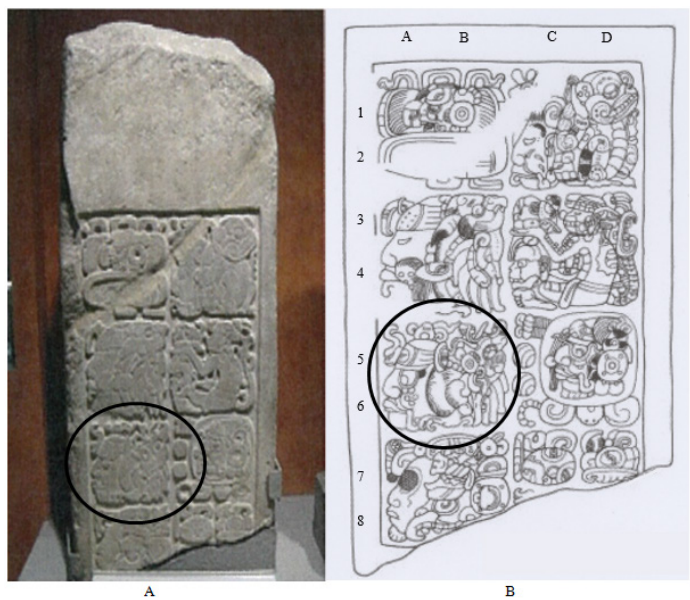

Figure 5. A) Yaxchilan Lintel 48 in the Museo de Cultura Maya, Chetumal, Mexico [36]. The glyph circled in red is Hun Ahau who becomes the Sun God. This glyph is also the Sun God personification of the number 4 in the Mayan date 9.4.8.11.16 / 2 Kib 19 Pax (long count / 52 year round dates), or Feb 13, 526.. Physically, the lintel is made of limestone and is $1.26 \mathrm{~m}$ high, $0.67 \mathrm{~m}$ wide, about $0.23 \mathrm{~m}$ deep, and weighs about $524 \mathrm{Kg}$. The dimensions of the sculpted area are $0.98 \mathrm{~m}$ high by $0.55 \mathrm{~m}$ wide. B) Cartoon of Lintel 48 by John Montgomery [37] with alpha/numeric position designators for glyphs. Again, the glyph circled in black (A5 and A6) is Hun Ahau. 
Joy b'alam (Knot-eye Jaguar I) was a vigorous warrior king who had the unpleasant habit of capturing nobles from neighboring city states with which he was at war. Presumably, they were kept as hostages to insure future peace Roman style. However, Knot-eye's military aspirations eventually lead to his downfall when he himself was captured by the rival city state of Piedras Negras sometime before $518 \mathrm{AD}$. This fact is known from Panel 12 at Piedras Negras [35]. Next, an interregnum followed without a strong leader. Perhaps an aspirant was hesitant to seize power in Yaxchilan if he thought Knot-eye was still alive in captivity. In any case, the interregnum was followed by the ascension of K'inich Tatb'u (Skull II; Knot-eye's brother) on 13 February 526 AD. In that year Lintel 48 was dedicated. The lintel shows a solar deity in location A5 and A6 of Figure 5 [36, 37]. Although this God head lacks a Kin (Sun) sign attached to it, he can be identified with confidence because 1) he is the personification of the number " 4 " in the Mayan long date 9.4.8.11.16, or Feb 13, $526 \mathrm{AD}, 2$ ) he has a headband with an Ahau sign (meaning "lord" [38]) in it, possibly referring to K'inich Ahau but probably a reference to Hun Ahau, one of the hero "Headband Twins" who later becomes the Sun in Mayan mythology [38], 3) he has the characteristic central protruding "buck tooth" (sometimes called an "egg tooth") of the Sun God, 4) he has a characteristic "handle bar mustache" called a mouth volute, and finally 5) he has a "Roman nose" [30]. All these features constitute a signature equivalent (see Figure 6) for a solar deity. And, most importantly for this study, this God head profile also has the three cheek spots, forming a small equilateral triangle, of the Sun God following periods of high solar activity (Figure 6).

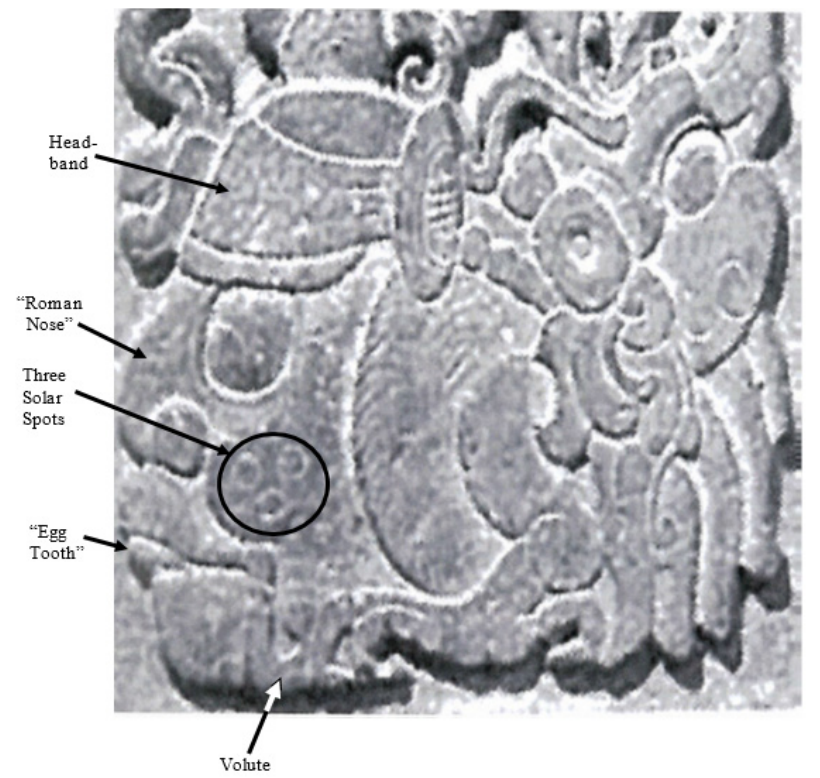

Figure 6. Close-up of Glyphs at locations A5 and A6 [36]

It should be noted that placing a triplet of sunspots within an image that is part of a date is not particularly unusual for the Maya. "Side information" was often included with dates to remove any possible ambiguity associated with positioning events in time. Both the Dresden and Madrid codices show this type of redundancy $[39,40]$.

\section{Historical Naked-eye Sunspot Observations and How They Were Made}

Large sunspots are naked-eye objects which, during multiple sunspot displays, can cover as much as $1 \%$ of the solar disk [41]. However, coverage in excess of only $0.05 \%$ of the central part of the solar disk allows naked-eye observation of sunspots [42]. Ancient observers employed several methods to reduce the Sun's brilliance (all unsafe) for thousands of years.

Islamic observers employed reflection from water to look at the Sun [18]. The method works as follows. When the Sun is at zenith, the ratio of the reflected solar power $\left(\mathrm{P}_{\mathrm{r}}\right)$ to the incident power $\left(\mathrm{P}_{\mathrm{i}}\right)$ from pure water (index of refraction $n=1.33$ ) is given by [43]

$P_{r} / P_{i}=[(1-n) /(1+n)]=(-0.33 / 2.33)^{2}=0.02=2 \%$.

Therefore, only $2 \%$ of the incident power is reflected back to the eye. With this reduction, and a little atmospheric haze or black ink in the water, it just might be possible to tolerate (perhaps with some eye damage) naked-eye solar observation. Perhaps the Maya observed the Sun's reflection in Lake Petén on a calm day.

In China, the fine dust of the Gobi Desert can remain suspended in the atmosphere by wind turbulence. Mei scattering then reduces the Sun's visible intensity to levels tolerable to the human eye. Mei calculations are complex, but a light ray with a wavelength of $5750 \AA$ (yellow light) scattered once from a dielectric quartz (sand; $\mathrm{n}=1.54)$ ) particle 0.9 microns in diameter (a diameter typical of fine air bourn desert dust) will lose approximately $0.13 \%$ of its intensity in the forward direction [44]. In other words, if a ray of light starts out with intensity (power) of one unit then, after a single scattering event of the type just described, its intensity (power) will be 0.99867 , the loss being primarily due to back scattering. That might not sound like much of a reduction, but in air carrying a lot of suspended dust, the accumulated reduction in the Sun's radiated power over a long distance can be quite substantial (Figure 7A) [45]. After 5200 scattering events, each reducing the power from the previous scattering event by a mere $0.13 \%$, the remaining power $\mathrm{P}_{\mathrm{r}}$ (note that here $\mathrm{P}_{\mathrm{r}}$ means remaining power not reflected power) is only

$$
\mathrm{P}_{\mathrm{r}} / \mathrm{P}_{\mathrm{i}}=[(0.99867) / 1]^{5200}=0.0010=0.10 \%
$$

of its original (incident) value $\mathrm{P}_{\mathrm{i}}$. In this example, scattering is 20 times more efficient at intensity reduction 
than reflection, while direct sunlight is attenuated by a factor of 1000. A similar, but less extreme, effect can be seen when viewing the Sun over water [45]; where micron sized salt spray particles $(\mathrm{n}=1.54)$ and water micro-droplets do the work of attenuation instead of dust (Figure 7B). The Maya probably made their observations this way at sunrise or sunset. And, the Greeks may have made similar observations over the Aegean. The Sun can be viewed in some comfort via Mei scattering. However, invisible ultraviolet rays are not as strongly attenuated by Mei scattering as visible light, and will eventually cause eye damage.

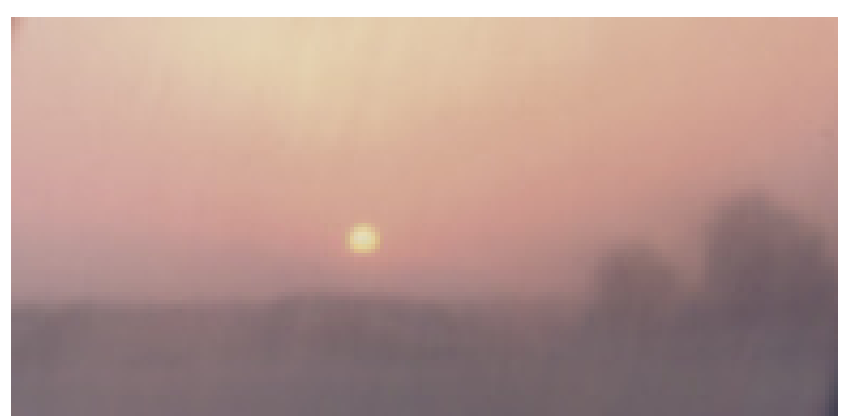

A

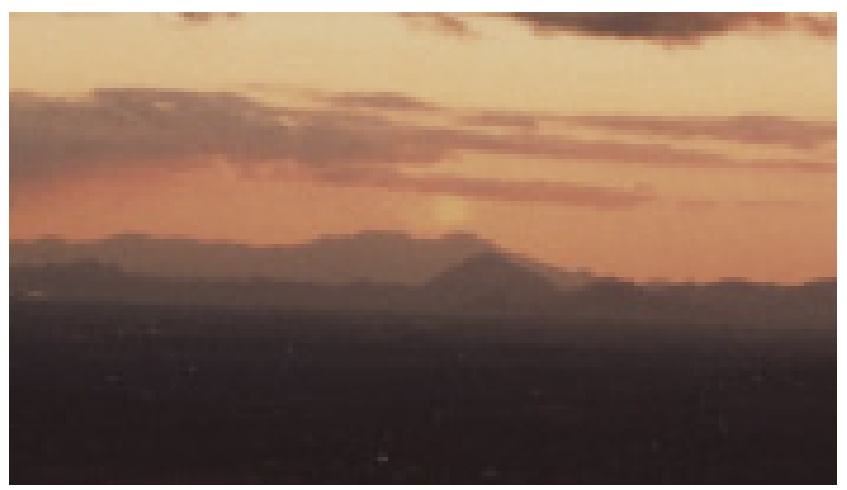

B

Figure 7. A) Sunset at the airport in Luxor, Egypt, October 17, 2009. The Saharan dust storm in the photograph above was particularly bad, as can be seen from the indistinct images of trees on the right. Chinese observers were probably confronted with conditions much less severe than this while studying the Sun in the Gobi Desert. No filtration was used on the author's camera. B) Sunset over water, looking toward Baja California. No filtration used. The Maya probably viewed the Sun this way. In either case, as these images of the solar disk show, viewing naked-eye sunspots is difficult. As a practical matter, only the largest displays (well above the theoretical minimal size for naked-eye observation) will generally be seen. Photos by author.

Japanese observers used smoked glass to make naked eye sunspot observations. In this case, a layer of carbon (smoke) particles of thickness $d$, does the work of absorbing incident optical power $P_{i}$ according to the Bouguer-Lambert Law [46],

$$
\mathrm{P}_{\mathrm{r}} / \mathrm{P}_{\mathrm{i}}=\mathrm{e}^{-\alpha \mathrm{d}} \text {, }
$$

where $P_{r}$ is the remaining power after $P_{i}$ passes through the smoke layer and $\alpha$ is the absorption coefficient equal to the inverse of the thickness required to reduce $\mathrm{P}_{\mathrm{i}}$ by a factor of $\mathrm{e}^{-1}$, where the base $\mathrm{e} \approx 2.71$. The constant $\alpha$ is typically a large number for visible light, so it does not take much smoke to reduce the Sun's brilliance. The obvious advantage of this method is that an observer doesn't need a desert, and there is no need to wait for the desired atmospheric conditions to make observations. Unfortunately, the absorption coefficient for ultraviolet light by glass and carbon smoke is not as large as one would like [47]. Therefore, UV will be passed with eventual consequent eye damage. Equations 1, 2, and 3, summarize in mathematical form the techniques used by ancient cultures to observe the Sun. Equation 1 is a rational algebraic function, equation 2 is a power law, and equation 3 is an exponential law. These laws provide progressively stronger solar attenuation, respectively, in the visible part of the solar spectrum.

Asian observations from China, Japan, and Korea cover a period from 28 B.C. (Julian calendar) to the 1604 A.D (Gregorian calendar) [3]. However, for the time period of interest in this report (the beginning of the $6^{\text {th }}$ century), it is the Chinese records contained within the Wei-shu (also written $\mathrm{Wei} S h u$ ) and the Nan-ch'i-shu (probably should be spelled Nan $Q i S h u$ ) that are of interest [3]. These references are a little confusing for westerners and deserve some explanation. Wei-shu literally means the Book of Wei. It was a history book written by Wei Shou (a name very similar to the title of the book itself). Because the Wei-shu is a history, its title is sometimes translated as the History of the Wei Dynasty. And, what is most important for this study, this history book recorded various astronomical portents (sunspots) [48]. The Northern Wei Empire (386-534 AD) stretched from the Yellow Sea westward into the Gobi Desert. It laid north of 33 parallel (approximately), and extended almost to the $45^{\text {th }}$ parallel, taking in part of modern-day northern China and southern Mongolia. Below this vast territory laid the short lived Southern Qi Empire (479-502 AD), another vast territory extending south to the Tropic of Cancer (approximately) and west from the Formosa Strait to the Gobi Desert (including much of modern-day southern China). The history of this empire is recorded in the Nan-ch'i-shu (literally Book of the Southern Qi, or more loosely translated as the History of the Southern Qi Dynasty) by Xiao Zixian. Again, astronomical portents were included in the text [49].

The $5^{\text {th }}$ century saw a complete pause in naked eye sunspot activity as recorded by Asian observers [3]. However, on July 4, 499 AD a sunspot was recorded in China by Wei Shou [3]. A further report came on January 29, $500 \mathrm{AD}$, again recorded by Wei Shou, and independently recorded by Xiao Zixian on January 30 of the same year [3]. Next, sunspots were recorded on September 4, 501, February 8, 502, and on March 26, 502, all by Wei Shou [3]. Again, there was a pause in solar activity- quite brief. But then, on March 17, $510 \mathrm{AD}$ a new series began, with additional sunspots on December 16, 
511 and April 7, 513. The sunspots of this last series were all recorded by Wei Shou in China [3]. No other naked-eye sunspots were recorded again until March 29, $566 \mathrm{AD}$ [3]. The event of April 7, $513 \mathrm{AD}$ is particularly intriguing because it occurred prior to, but close to, Knot-eye's capture. In those early classic times a chance pattern had been established in which naked eye sunspot displays seemed to be prognosticators of political change in the next few years. The Teotihuacan ambassador Fire Born reached Tikal 3 years after the sunspot display of 375 AD [32]. Curl Snout took control in Tikal 4 years after the 379 display, and he died 4 years after the $400 \mathrm{AD}$ display [33]. Now, Knot-eye was captured perhaps 4 or 5 years after the display of $513 \mathrm{AD}$. All these events would have captured the imagination of Mayan diviners.

\section{Carbon-14 Measurements}

Naked-eye observations can never be relied on completely because there is apt to be confusion between sunspots and observed atmospheric phenomena. Furthermore, observers can simple cease to make observations. An observer may die and have no students, or political/economic events can disrupt his studies, or perhaps certain types of observations simply fall out of fashion. In any case, physical corroboration is important, and atmospheric carbon-14 measurements are the tool of choice for assessing solar activity levels in the past. The method works as follows.

An active Sun ejects a large number of solar wind particles that can change the magnetic properties of the solar wind and the Earth's geomagnetic field. As magnetic shielding properties increase during an active Sun $[50,51$, 52], nitrogen rich lower layers of the atmosphere are partially screened from high energy cosmic rays that are indirectly capable of transmuting naturally occurring nitrogen-14 $(99.63 \%$ of all $\mathrm{N})$ into carbon-14 via nuclear reactions. The reverse is, of course, true when the Sun is in a quiet phase (i.e. the atmospheric ${ }^{14} \mathrm{C}$ level increases). Therefore, the amount of ${ }^{14} \mathrm{C}$ produced in the atmosphere is modulated by the level of solar activity. The variations are typically small, on the order of 0 to 100 parts per thousand (or "ppt", denoted by the symbol \%o) above or below the average (mean) ${ }^{14} \mathrm{C}$ level relative to the total amount of stable atmospheric carbon $\mathrm{C}$; where $\mathrm{C}={ }^{13} \mathrm{C}+{ }^{12} \mathrm{C}$. This radiocarbon anomaly (denoted by $\delta$ ) is given by [53]

$$
\begin{gathered}
\delta^{14} \mathrm{C}=\left\{\left[\left({ }^{14} \mathrm{C} / \mathrm{C}\right)_{\text {sample }}-\left({ }^{14} \mathrm{C} / \mathrm{C}\right)_{\text {mean }}\right] /\left({ }^{14} \mathrm{C} / \mathrm{C}\right)_{\text {mean }}\right\} \mathrm{x} \\
10^{3} \% \text {. }
\end{gathered}
$$

The subscript sample in equation 4 above refers to an ancient sample of atmospheric carbon. Where do such samples come from? Atmospheric ${ }^{14} \mathrm{C}$ eventually becomes radioactive carbon dioxide and, together with stable non-radioactive carbon dioxide, is eventually used by trees during photosynthesis. The wood of each tree ring contains the mix of carbon isotopes from the year in which it was formed. So, a chronology can be formed that relates atmospheric ${ }^{14} \mathrm{C}$ levels to a Gregorian date after correcting for radioactive decay (the half-life of ${ }^{14} \mathrm{C}$ is about 5000 years).

However, physical data like atmospheric ${ }^{14} \mathrm{C}$ measurements have their drawbacks as well. For example, ${ }^{14} \mathrm{C}$ changes do not reveal the "fine structure" of solar changes. The sheer size of the ${ }^{14} \mathrm{C}$ reservoir tends to average out solar behavior over several "11-year" sunspot Schwabe cycles. Also, "isotopic fractionation" occurs due to the chemical reactions in a living tree that may favor lighter (stable) isotopes of carbon over the heavy radioactive isotope. That is to say, biochemistry can upset the isotopic ratios. After reversing the effects of isotopic fractionation on $\delta$, a corrected radiocarbon anomaly $\Delta{ }^{14} \mathrm{C}$ can be calculated. And, it is this corrected radiocarbon anomaly that is graphed in Figure 8 for the first millennium.

In spite of its shortcomings, ${ }^{14} \mathrm{C}$ measurements give important general information about solar behavior. The ${ }^{14} \mathrm{C}$ versus time curve had a maximum near $450 \mathrm{AD}$, but in the year $513 \mathrm{AD}{ }^{14} \mathrm{C}$ levels were at the bottom of a trough (Figure 8 [33]). That is to say, the solar quiescent $5^{\text {th }}$ century is consistent with the ${ }^{14} \mathrm{C}$ data, as is the increase in solar activity at the beginning of the $6^{\text {th }}$.

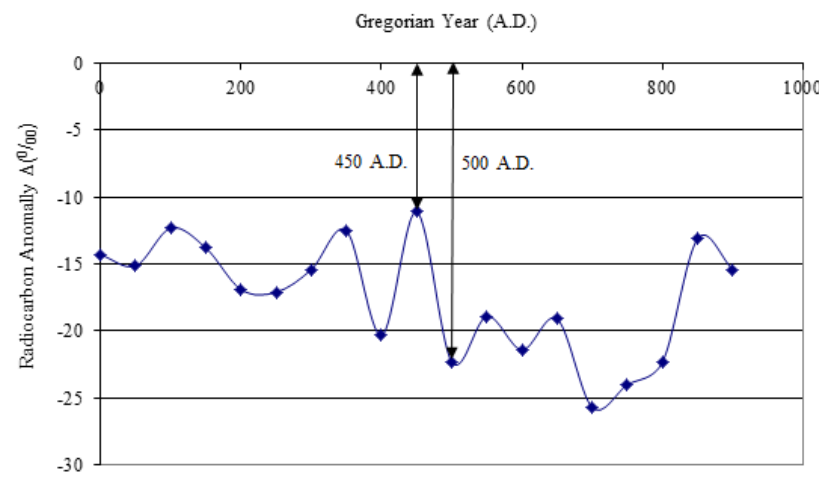

Figure 8. The corrected radiocarbon anomaly $(\Delta)$ measured in parts per thousand $(\% 0)$ for the first millennium of the Common Era [33]. Graph by author.

\section{Tree Ring Measurements}

The tree ring data of figure 9 is a record of average ring widths for Pinus Longaeva (Bristle Cone Pine) from 495 to $515 \mathrm{AD}$ [54]. High sunspot activity correlates with drought years in the southwestern part of the United States (narrow tree rings). However, the correlation is not perfect and extra $E l$ Niño events can occur which can make the climate abnormally damp (wide tree rings). Such interference was not a problem for this 20 year set of data. The site used to sample the American southwestern climate was Methuselah Walk in the White Mountains of California. This is the best data set available because 1) these are the oldest trees in the U.S. with ages stretching back to Mayan 
times, 2) the rings of the Bristle Cone Pine are minimally affected by the previous year's growth, 3) the sample rate was high, 25-26 samples per year, a factor that is very important for subjects as variable as living organisms, and 4) all data from Methuselah Walk was collected by a single researcher (D.A. Graybill), thereby minimizing variability due to different techniques [55]. The tree ring growth trend line shows a steady decrease from the high pre-sunspot values to clearly reduced growth by the end of high solar activity. Furthermore, the comparison of dips in the tree ring growth pattern with naked eye sunspot activity is equally clear. The dips at 501 and $513 \mathrm{AD}$ are probably associated with the sunspot clusters of $499 / 500 / 501 / 502 / 502$ and 510/511/513 respectively. Notice how the bottoms of these dips in the data line lag the centroid of sunspot event clusters by 2 or 3 years. There is a delay before climate change manifests itself in growth changes. Tree ring data together with C-14 measurements reinforce the idea that the Asian naked-eye observations were true sunspot events and not just atmospheric phenomena.

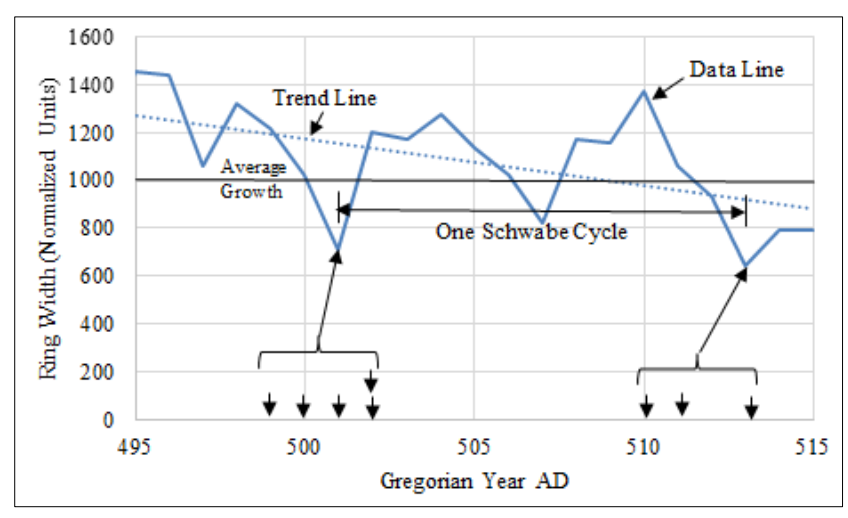

Figure 9. The arrows along the time axis mark the years of great sunspot displays. Tree ring data is for the annual June to August growth of Pinus Longaeva (Rocky Mountain Bristle Cone Pine). Tree ring widths are from the International Tree Ring Data Bank [54]. Widths are in "normalized" units such that 1000 represents average growth. A "width" less than 1000 indicates drought conditions, and above 1000 indicates wet conditions. Climate normally accounts for $63 \%$ of the growth variance [55]. The site used to sample the American southwestern climate was Methuselah Walk in the White Mountains of California. All data from Methuselah Walk was collected by D.A. Graybill [50] and involved 25 to 26 samples per year for the 495-515 AD time intervals. Graph by author.

\section{Corroborating Artifact from Belize}

There is another corroborating Mayan record of the naked-eye sunspot cluster (actually a double cluster) observed circa 500 AD. Colas, et al. [56] have described two pottery artifacts excavated from the $3^{\text {rd }}$ structure 2 of the Bedran group of the Baking Pot site in the Belize Valley (Figures 1, 10,11). These artifacts have been dated to 370-500 $\mathrm{AD}$ on the basis of stylistic and epigraphic analysis, and 370-550 AD on the basis of ceramic analysis. One of the pieces, a small bowl (cup) referred to as Vessel 2 , has a band of incised glyphs encircling the exterior of its midsection (Figure 12). The glyphs A through E are a statement of purpose and read something like, "It came to pass [that this] was created [as a] cup [for] fresh cacao." Glyphs F through I contain the owners name and his earthly and divine titles. These glyphs roughly translate to, "[for] Hummingbird Cloud, four water lord, [the] heart [of the] Sun God." The last glyph (I) is the Sun God (k'inich Ahau) with a kin sign tattooed to the back of his head. And, most importantly from the standpoint of this report, the Sun God is spotted. The spots, as is often the case, form a small equilateral triangle on the cheek. Considering the cluster of 5 naked eye sunspot events recorded in Asia [1] from July 4, $499 \mathrm{AD}$ to March 26, $502 \mathrm{AD}$, and a cluster of 3 more events from March 17, 510 to April 7, 513, it seems reasonable to date Vessel 2 to ca. $500 \mathrm{AD}$ because this date is consistent with the stylistic analysis, epigraphic analysis, ceramic analysis, Asian sunspot observations, ${ }^{14} \mathrm{C}$ measurements, and tree ring analysis. It is very fortunate to have two artifacts from two different parts of the Mayan cultural zone, created in the same general time period, that both show a spotted Sun God. It is a coincidence that is suggestive of an active Sun in the early part of the $6^{\text {th }}$ century and of the wide spread practice of solar observation in the Mayan cultural zone.

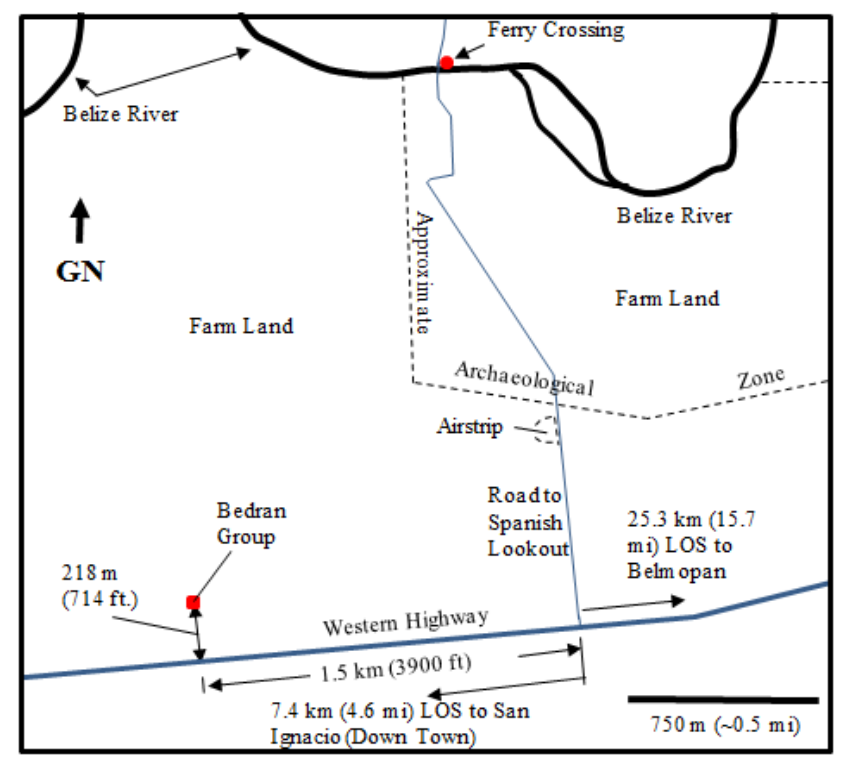

Figure 10. Bedran / Baking Pot site, Belize. GN is the geographical north. The red square marks the location where the study artifact (Vessel 2) was found. There have been many changes in this area since it was first surveyed [52]. Some damage has been done by cultivation, and an airstrip now exists to service the region. Even the course of the Belize River has been slightly changed for irrigation purposes. Fortunately, the Bedran Group has remained intact. Map by author. 


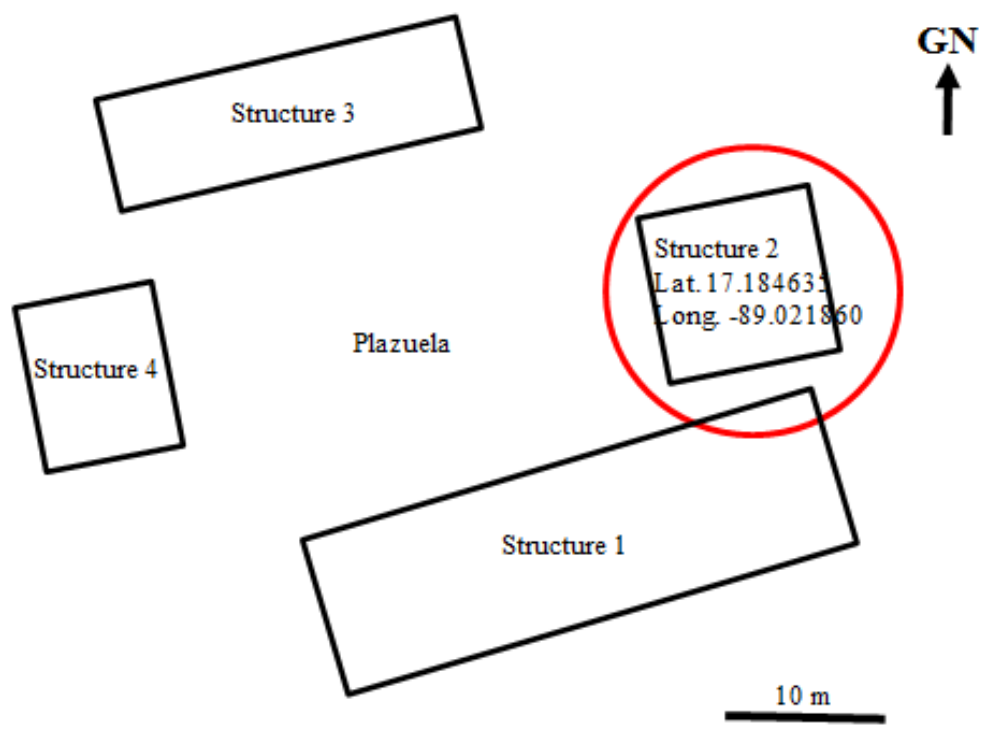

Figure 11. Major structures 1 through 4 surrounding the plazuela. The red circle marks structure 2 where the study artifact (Vessel 2) was found. GN is the geographical north. Map by author.

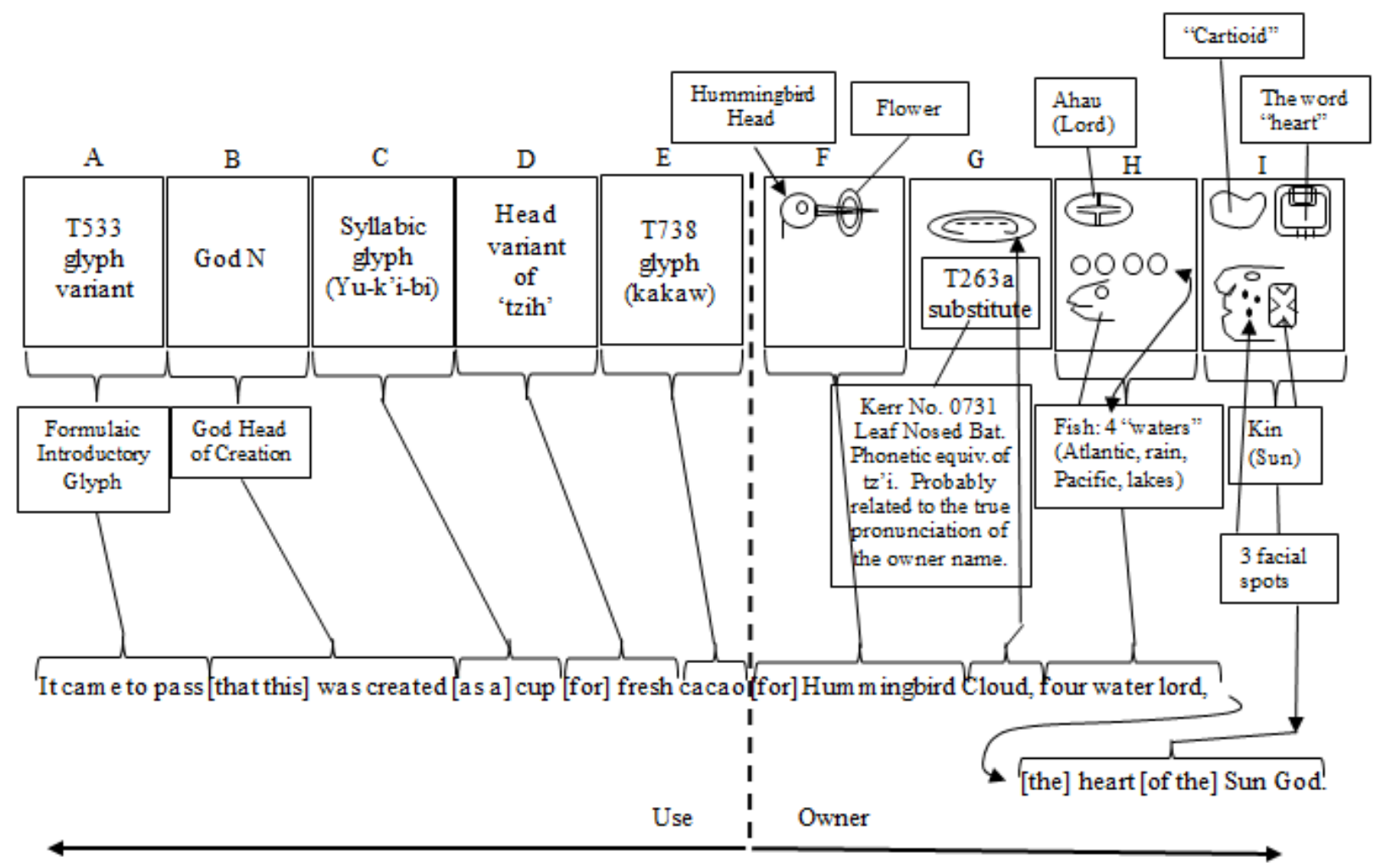

Figure 12. Inscription on the outside of Vessel 2, with translation. Note the spotted Sun God. The drawings of glyphs are not intended to be realistic renderings, but mealy indicate location of stated graphic devices. "T" numbers are Thompson glyph numbers [57], and the phonetic translation of the Kerr No. 0731 Leaf Nosed Bat glyph has been discussed by E. Boot [58]. Drawing by the author.

\section{Summary and Conclusion}

Knot-eye was captured on or before $518 \mathrm{AD}$, perhaps 4 or 5 years after the cluster of naked-eye sunspot events that terminated in $513 \mathrm{AD}$. It could not have escaped the notice of Mayan priest/astronomers that this pattern had occurred before in proximal times. When Skull II took power, he was quick to capitalize on that fact. The inclusion of the spotted Sun God on monumental Lintel 48 advertised the fact that Knot-eye was gone, and a new political era had begun, with a new strong man.

The Asian sunspot record spans the time period from May 10, $28 \mathrm{BC}$ to Oct. $251604 \mathrm{AD}$ when observation by telescope took over [1]. However, there are notable gaps in 
the record. For example, between the observations of Dec. 6, $400 \mathrm{AD}$ and July 4, $499 \mathrm{AD}$, no naked eye spots were recorded. The question is, "Was there a real decrease in solar activity, or was the gap in the record due to a lack of interest in making such observations?" Clark and Stephenson [1] have attributed the lack of records during this period as due to political instability and rapid dynastic changes. The Mayan record seems to support the position that the $5^{\text {th }}$ century was a time of the quite Sun, since the spotted Sun God disappears during this time interval but is apparent both before and after. Tikal Stela 31 records the termination of the sunspot series ending in 375 AD. Stela 1 records the absence of sunspots circa $450 \mathrm{AD}$ [37]. And, both Lintel 48 and Belize Vessel 2 record the reemergence of sunspot events that terminated in 513 AD. The fact that two independent cultures, on opposite sides of the planet, completely isolated from one another by vast oceans, should have recorded a gap in the sunspot record for the same time interval is compelling.

One last point demands attention. All spotted Mayan Gods are not created equal. That is to say, a God may display spots without there being any reference to physical sunspots at all. For example, in the glyph block above the solar deity labeled Ahau, in lintel locations A3 and A4, there is a lunar deity whose characteristic hook shaped beard and feline facial features identify him as Yax Balam (Xbalanque) or the hero "Jaguar Headband Twin" (Hun Ahau's brother). His name means the "Sun's hidden aspect" ( $B$ 'alam can mean hidden or jaguar) and is an oblique reference to the moon, which shines at night when the nocturnal jaguar is active, and when the Sun is "hidden" under the Earth [38]. Therefore, in this case, the spots around the mouth of this glyph are probably jaguar spots, which together with the feline features of this glyph form a kind of written pun. Finally, it should be noted that even casual naked-eye observation of the Moon reveals light gray patches forming a "man in the moon" (or "rabbit" for the Maya), and not a uniform silvery disk. So, from the standpoint of appearance, a spotted lunar deity makes sense. Furthermore, the spots on the lunar God head are always present like the markings on the moon. As this example shows, spots can be employed in Mayan iconography for a variety of reasons and are a common design element. In the reports of this series only spotted solar deities are considered.

\section{REFERENCES}

[1] Damon PE, Sonett CP. Solar and Terrestrial Components of the Atmospheric ${ }^{14} \mathrm{C}$ Variation Spectrum. In: Sonett $\mathrm{CP}$, Giampapa MS, Matthews MS, editors. The sun in time. Tucson: Univ. of Arizona Press; 1991. p. 360-388.

[2] Castagnoli GC, Bonino G, and Provenzale A. Solar-Terrestrial Relationships in Recent Sea Sediments. In:
Sonett CP, Giampapa MS, Matthews MS, editors. The sun in time. Tucson: Univ. of Arizona Press; 1991. p. 562-586.

[3] Clark D, Stephenson FR. An Interpretation of the Pre-Telescopic Sunspot Records from the Orient. Q. Jl. R. Astr. Soc. 1978 Dec; 19: 387-410.

[4] Ruggles C, Ancient Astronomy: An Encyclopedia of Cosmologies and Myth, 2005, ABC Clio

[5] Thurston H, Early Astronomy. New York (NY): Springer-Verlag; 1994. 268p.

[6] Kõiva M, Pustylnik I, Vesik L editors. Cosmic Catastrophes, Proceedings of the SEAC 2002. Tartu (Estonia): Esti Kultuurkapital; 2005. 214p.

[7] Chamberlain VD, Carlson JB, Young MJ, Ruggles C editors. Songs from the Sky. W Sussex (UK): Ocarina Books; 2005, $379 \mathrm{p}$.

[8] Malville JM, Swaninathan RN. Surya Puja Temples of South India. Archaeoastronomy 1996 Jan: 12: 310-19. Also see $p$ 315 of reference 5 .

[9] Robinson A. The Story of Writing: Alphabets, Hieroglyphs \& Pictograms. London (UK): Thames \& Hudson; 1995. p. 145,175 .

[10] Coyne GV. Sunspots: The Historical Background. In: Sonett CP, Giampapa MS, Matthews MS, editors. The sun in time. Tucson: Univ. of Arizona Press; 1991. p. 3-10.

[11] Kondrashov D, Feliks Y, Ghil M. Oscillatory Modes of Extended Nile River Records (A.D. 622-1922). Geophy. Res. Let. 2005 May; 32(10): p. L10702.

[12] Zito RR. Possible Mesoamerican Naked-Eye Observation of Sunspots-II: Evidence from the Codices. In: Rappengluck MA, Rappengluck B, Campion N, Silva F, editors, Astronomy and Power: How Worlds Are Structured, Proceedings of the SEAC 2010 Conference. Oxford (UK): BAR 2794; 2016. P. 205-9.

[13] Seidel M. The Valley of the Kings. In: Schulz R, Seidel M, editors. Egypt: The World of the Pharaohs. New York (NY): Konemann; 2002. p.226.

[14] Belmonte JA, Shaltout M, and Fekri M. Astronomy, Landscape, and Symbolism: A Study of the Orientation of Ancient Egyptian Temples. In: Belmonte JA and Shaltout M, editors. In Search of Cosmic Order: Selected Essays on Egyptian Archaeoastronomy. Cairo (Egypt): Supreme Council of Antiquities Press; 2009. p. 215-83.

[15] King D. The Orientation of Medieval Islamic Religious Architecture and Cities. J. for the History of Astron. 1995 Aug; 26(3): p. 253.

[16] King D, Gingerich O. Some Astronomical Observations from Thirteenth-Century Egypt. J. for the History of Astron. 1982 June; 13(2): p. 121.

[17] Nasr SH. Islamic Science: An Illustrated Study. London (UK): World of Islam Festival Publishing Co.; 1976. p. 98.

[18] King DA. Islamic Astronomy. In: Walker C, editor. Astronomy Before the Telescope. London (UK): British Museum Press; 1996. p. 143-74.

[19] Vaquero JM. The Sun Recorded Through History: 
Astrophysics and Space Science Library, Vol. 361. Dordecht (Germany): Springer; 2009. p. 57-101.

[20] McCutcheon RA. Book Review (in English) on "Astronomy of Ancient Russia" (in Russian). J. for the History of Astron. 2008 Aug; 39(3): 412-4.

[21] Svyatskiy D and Gorodetskiy ML. Astronomiya drevnei Rusi. Moscow: Russkaya Panorama; 2007. 663p.

[22] Solheim JE. The Northern Light as Messenger from the Other World and Harbinger of War and Disaster. In: Kõiva M, Pustylnik I, Vesik L editors. Cosmic Catastrophes, Proceedings of the SEAC 2002. Tartu (Estonia): Esti Kultuurkapital; 2005. p. 167-74.

[23] Healy JF. Pliny the Elder- Natural History: A Selection. London (UK): Penguin Books; 1991. p. 22, 28.

[24] Galindo Trejo J and Allen C. Maya observations of $13^{\text {th }}$ century transits of Venus? In: Kurtz DW, editor. IAU Colloq. 196: Transits of Venus: New Views of the Solar System and Galaxy. Cambridge (UK): Cambridge U. press; 2005. p. 124-37.

[25] Brody J. The Enigma of Sunspot: A Story of Discovery and Scientific Revolution. Edinburgh (UK): Floris Books; 2002. $191 p$.

[26] Schuster AMH. Epi-Olmec Decipherment. 1997 July. www.archaeology.org/online/news/la.mojarra.html. Accessed Oct. 3, 2016.

[27] Amber JR. The Anasazi: Prehistoric People of the Four Corners Region. Flagstaff (AZ): Museum of Northern Arizona, 1977. p. 6, 25.

[28] Fialko VC. El marcador de juego de pelota de Tikal: nuevas referencias epigráficas para el períod clásico temprano. Mesoamérica 1988 June; 15: 117-35.

[29] Zito RR. Possible Mesoamerican Naked-Eye Observation of Sunspots - III: Evidence from the Hauberg Stela. In: Šprajc I, Pehani P (editors). Ancient Cosmologies and Modern Prophets, Anthropological Notebooks, Year XIX Supplement. Ljubljana (Slovene): Slovene Anthropological Society; 2013. P. 339-46.

[30] Milbrath S. Star Gods of the Maya: Astronomy in Art, Folklore, and Calendars. Austin (TX): U. of Texas Press; 1999. p. 58-104.

[31] Aveni AF. Skywatchers. Austin (TX): U. of Texas Press; 2001. 410p.

[32] Zito RR. Possible Mesoamerican Naked-Eye Observation of Sunspots-I: Evidence from the Tikal Ball Court Marker. In: Rappengluck MA, Rappengluck B, Campion N, Silva F, editors, Astronomy and Power: How Worlds Are Structured, Proceedings of the SEAC 2010 Conference. Oxford (UK): BAR 2794; 2016. P. 193-6.

[33] Zito RR. Possible Mesoamerican Naked-Eye Observation of Sunspots - IV: Evidence from Tikal Stela 31. In: Šprajc I, Pehani P (editors). Ancient Cosmologies and Modern Prophets, Anthropological Notebooks, Year XIX Supplement. Ljubljana (Slovene): Slovene Anthropological Society; 2013. P. 347-55.

[34] Zito RR. Possible Mesoamerican Naked-eye Observation of Sunspots-V: Evidence from Rio Azul Tomb I Murals and
Related Artifacts. Sociology and Anthropology 2016 4(11): 953-965.

[35] Martin S and Grube N. Chronicle of the Maya Kings and Queens. London (UK): Thames and Hudson; 2000. p. 10, 116-121, 141.

[36] Travis S. Yaxchilan \& La Pasadita [internet]. [Cited May 20, 2013].

http://pinterest.com/luconomics/yaxchilan-lapasadita-maya steden-in-mexico/.

[37] Montgomery J. Virtual Mesoamerican Archive: Foundation for the Advancement of Mesoamerican Studies (FAMSI): Yaxchilan: Lintel 48.

http://vma.uoregon.edu/inst_doprofile.lasso?\&DoWhat=d\& Document=639. Accessed May 23, 2011.

[38] Tedlock, D. Popol Vuh. New York (NY): Simon \& Schuster; 1996. p. 141, 239, and 287.

[39] Villacorta CA and Villacorta CJA. The Dresden Codex. Walnut Creek (CA): Aegean Park Press; 1930. p. 44-45.

[40] Vail G and Aveni A. The Madrid Codex. Boulder (CO): U. Press of Colorado; 2004. p. 181.

[41] Murdin, P, Allen D. and Malin D. Catalogue of the Universe. New York: Crown; 1979. p. 159-170.

[42] Bray RJ. and Loughhead RE. Sunspots. London (UK): Chapman and Hall; 1964. p. 229.

[43] Lorrain P. and Corson DR. Electromagnetic Fields and Waves, $2^{\text {nd }}$ ed. San Francisco (CA): Freeman; 1970. p.518.

[44] Born M and Wolf E, Principles of Optics. Oxford (UK): Pergamon Press; 1965. p.645, 651, and 654.

[45] Meinel A and Meinel M, Sunsets, twilights, and evening skies. Cambridge (UK): Cambridge U. Press; 1983. p.84-5 and plate 2-2 (left). Photo taken from the Pacific coast of northern Mexico.

[46] Jenkins FA and White HE. Fundamentals of Optics, $3^{\text {rd }}$ ed. New York (NY): McGraw Hill; 1957. p. 200, 447.

[47] Gray DE (editor). American Institute of Physics Handbook, $3^{\text {rd }}$ ed. New York (NY): McGraw Hill;1972. p. 6-93.

[48] Wei Shou. Wei-shu. (or History of the Wei Dynasty). Ch. 105/a (Heavenly Phenomena).

[49] Xiao Zixian. Nan-ch'i-shu (or History of the Southern Qi Dynasty). Ch. 12 (Astronomy).

[50] Stuiver M, Quay PD. Changes in atmospheric carbon-14 attributed to a variable sun. Science. 1980 Jan; 207 (4426): $11-9$.

[51] Bard E, Raisbeck GM, Yiou F, Jouzel J. Solar modulation of cosmogenic nuclide production over the last millennium: comparison between ${ }^{14} \mathrm{C}$ and ${ }^{10} \mathrm{Be}$ records. Earth and Planetary Science Letters. 1997 Aug; 150: 453-62.

[52] Beer, J. Long-term indirect indices of solar variability. Space Science Reviews. 2000 Nov; 94: 53-66.

[53] Faure G. Principles of Isotope Geology. New York (NY): John Wiley; 1977. P. 305-321.

[54] NOAA, 2009, Tree Ring Data Bank; 2009 [Cited 2009 May 
11]. Available from www.ncdc.noaa.gov/paleo/ treering.html.

[55] Fritts, HC. Tree Rings and Climate. Caldwell (NJ): Blackburn; 1976. p. 90, 153, 200-201, 223, 379 .

[56] Colas PR, Helmke GB, Awe JJ, and Powis TG. "Epigraphic and Ceramic Analysis of Two Early Classic Maya Vessels from Baking Pot, Belize,” Mexicon, 2002 April; Vol. XXIV:
$33-39$.

[57] Thompson JES. A Catalog of Maya Hieroglyphs. Norman (OK): U. of OK Press; 1962.

[58] Boot E. The Bat Sign in Maya Hieroglyphic Writing: Some Notes and Suggestions, Based on Late Classic Ceramics. Published as an "Essay" on Mayavase.com, version of Feb. 20, 2009. Accessed Nov. 7, 2017. 